\title{
GENERAL DISGUSSION
}

THE final session of the symposium included a general discussion under the chairmanship of Dr M. Mellor.

M. Mellor: We are now going to start our final session, with the hard cases still remaining. We are going to have a discussion on the week's proceedings, and we will call upon four different people to start off the discussion. We shall break the discussion into four areas: deposited snow, ice bearing strength and ice forces, avalanches and blowing snow, and finally friction and adhesion. We will also save a little time for sundry topics. To introduce the first period of our discussion, I will ask Dr Kry of Imperial Oil to start us talking on deposited snow.

\section{DEPOSITED SNOW}

P. R. KRY: My overall impression of our state of understanding of deposited snow is that we have raised a sufficient number of questions at this symposium to guarantee an overwhelming number of contributions for the next one. In some areas we appear to be better off than in others; it seems that we have a somewhat good understanding of methods of deposition of the snow in drifting, but we seem to need more data to refine the theories of the model, and there may still be questions about the appropriate parameter values. However once the snow is deposited it seems to provide a blanket over our knowledge that is only slowly being withdrawn. We are a long way from producing quantitatively the mechanical development of the snow-pack from the boundary conditions, that is primarily the meteorological and geographical conditions. We know qualitatively, and have done for many years, about metamorphic changes in the snow-pack, but I feel there is still both a lack of quantitative expression of these metamorphic changes, and particularly a lack of knowledge of what these structural changes mean for the variation of mechanical properties. This lack most seriously affects the quantitative prediction of instability conditions in the snow-pack, that is what is really needed for avalanche forecasting, and that is where we are falling down.

The acoustic emission observations indicate great potential as an observational tool. However there are still the questions of the real emission sources, the types of emissions, and what are the most appropriate signals to observe.

Despite the lack of fundamental understanding of structural influences on creep and glide, it appears that we can calculate the forces on supporting structures, although we may need to review and to up-date some of the standards. Again on a different subject and from the standpoint of an applied problem, I think we have seen at this symposium a very good paper on the interaction of an explosive charge with the snow cover, a subject that has needed some work.

When it comes to the disappearance of the snow-pack, excluding avalanches of course, the situation is relatively a little better. Quantitative results on melt-water run-off can be obtained in some conditions, however this is not to say that this, or any of the problems that I have mentioned, are completely solved.

W. F. WeEks: I feel that one of the real difficulties is a problem that I think we mentioned during the first day. Someone first complained that all we always did was to take any snow parameter we could think of and correlate it with density, and then they said "is there nothing better than density?"'. Of course the reason everyone uses density is that it is so convenient and it works. It would, of course, be nice to use parameters that give us a more direct description of the structure of the snow but in the past this has been very time-consuming. It is however obvious from reading the current literature that we are making progress toward a 
time when we will be able to obtain good structural information in a short period of time. When such information becomes available it should herald a breakthrough in our understanding of the behaviour of snow.

S. C. ColBEGK: One thing which needs more emphasis is that, although we often understand the physics of the processes that we are interested in, and we may have some feel for what the properties of the snow cover or ice mass are, we often do not have methods of gathering the necessary data and getting it back to the position where the decisions are made. This becomes very evident in hydrology, for example, where you have a large relief in a mountainous area; at the bottom of the mountain you may have rain, at the top of the mountain you may have snow, both at the same time, and yet the hydrological forecaster who is sitting down in the valley may not really know what the conditions are in the area for which he is trying to make his forecast. Many of these problems will ultimately be solved by remote-sensing tools which are currently under active development. The point has often been made, and needs to be stressed, that we as glaciologists need to co-ordinate with people who are developing these remote-sensing tools, to make sure that they develop the tools which will be most beneficial. Rather than just developing tools for the sake of developing tools, let us help them develop the ones that we really need to apply to our problems.

E. R. LaChapelle: I would simply like to support the statement from Sam Colbeck and mention that in our own work in the Pacific North-West, in the Cascade Mountains, we have been driven into exactly this by necessity, in the framework of avalanche forecasting rather than snow-melt run-off forecasting, where nevertheless we encounter the same problem for freezing level and the amount of precipitation in the mountains and so forth. We need to know these things in real time, and by necessity we are gradually trying to develop some telemetry and some remote-sensing capabilities to handle this problem. I can only agree wholeheartedly with the statement from Colbeck that this is what we need and a lot more of it if we are going to do real avalanche forecasting and really accurate snow-melt run-off forecasting.

L. Davis: I agree fully with LaChapelle and Colbeck, but I think it is important that we as scientists let those people in remote sensing know what physical properties need to be measured. It seems to me that all too often remote-sensing techniques measure the minor properties rather than the major properties.

MeLLoR: I think we are picking up a common thread in these last three comments and it is one that seems important to me. A great effort is being made in remote sensing, using imagery from aircraft and satellites that are inherently expensive. The question is: are we doing enough to learn the behaviour of the materials that we are looking at? Do we know what these signals mean? I am not sure that we do, at least to an adequate degree. Maybe somebody can set us straight on that.

O. LøKEN: There is a related problem here and that is how hydrologists use these data. In the old days we got spot data from individual rain gauges in the river basin; by the use of remote-sensing techniques we are now getting images, areal information, or linear scans, and this type of data calls for another type of hydrologic model. I therefore think we ought to give some attention to the development of new hydrologic models so that we can effectively use the remote-sensing data when we get it. Are we doing enough in this regard?

Mellor: The data you are gathering are essentially distribution data. To what extent can you get total water quantities? What do you know about the depth of the snow cover or its water content, its density? Perhaps not too much under present circumstances without ground control. 
LøKen: That is another problem.

Mellor: I have heard some people talking about using satellite imagery to measure depth, density, distribution, grain size and all sorts of things, but nobody seems to have a clear idea of how this is to be achieved, and maybe it cannot be achieved with the sort of data we are gathering.

G. J. Young: We have heard several papers which assumed very simple conditions-particularly I am thinking about flat ground; all the ground we saw in the diagrams was flat, whereas in reality there is a lot of microrelief which is extremely important both for accumulation and for melt processes. I was surprised that not more was discussed about microrelief and about its effect on spatial variability of snow cover.

Mellor: Can we ask Dr Weeks whether this is the sort of thing that might have been addressed in any of the work he has been associated with on AIDJEX?

WeEks: We have done a lot on the use of lasers to study ice relief. You might use some of these techniques to study the surface roughness of the snow-pack. To the best of my knowledge this has never been done.

MELLOR: I was thinking of something on a finer scale which might be equivalent to the sort of thing S. L. Dingman used to do at the time he left CRREL; looking at slope exposures for hydrologic and frozen-ground considerations, and the effects of surface angle and of orientation to the sun and wind.

LACHAPELle: I could mention in that respect that N. Untersteiner and I began an enterprise of this nature to computerize the analysis of terrain element by element. It was rather a simplistic study but it was aimed at glaciology - lines of flow and so forth. Unfortunately Dr Untersteiner has gone off in one direction and I in another and we never published any of this, but it is possible with modern techniques to do quite a bit in this direction.

L. W. Gold: My comment is a complete shift in direction, I only want to mention that I found it very interesting that at a conference on applied glaciology we have had no papers on snow removal, and in fact when you look at the information that has been presented you find that it has been on those topics which are of particular interest to scientists at the present time. When you look at the problems of snow removal, I think there has been some progress made since the days of Bucher, but not too much has been done in that field since that time, and when you look at the amount of money that is spent on snow problems in Canada, the United States, Europe and the U.S.S.R. you find that probably more money goes down the drain every winter on this problem than on any other. Perhaps as applied glaciologists we should remind ourselves that there are some problems around that still require attention. There are some interesting questions that still have to be answered with respect to snow and how it moves, how it is displaced and how it might be picked up in an efficient and most economical manner, how it might be transported to some area where it is not quite the nuisance that it is in the centre of cities and in residential areas.

MELLOR: I agree with you entirely. I mentioned that in my paper and I have got it on a little list of future topics that somebody ought to wrestle with. If you have ever been to any of those Eastern Snow Conferences-the working man's symposia on applied glaciology-you will know that it is very much of concern to many people.

LACHAPELLE: I suggest you add snow making to that list if it is not there already.

MELlor: I think we should move on now to the next topic and I will ask Don Nevel to start us off discussing ice forces and bearing capacity. 


\section{ICE FORCES AND BEARING CAPACITY}

D. E. Nevel: In the past half-dozen years the activity in trying to understand ice forces has greatly increased, as you can tell by this conference. I would like to quickly review what has taken place here and then toss out a couple of ideas to open up the discussion.

First of all we need methods to calculate things. We had one paper along that line, the invited paper by P. Tryde. We are interested in building sloping structures: we had a couple of papers on that line, one concerned with modelling authored by R. Y. Edwards and K. R. Croasdale and another one by J. V. Danys and others from Canada where they are actually building such structures in the St Lawrence River. I think Mr Danys was emphasizing the importance of friction on these structures; this problem is also very important to the icebreaker people, which is another type of structure. Yet another type of structure which has been built is lightweight structures which are quite flexible. We had one paper on this by J. Swamidas and others although Mr Määttänen from Finland is also here and he is very interested in that subject. Another type of structure is a small vertical structure, and we had a couple of papers on that, one by K. R. Croasdale and others on fairly large indentors that were used on a lake, and then we had a small-scale laboratory investigation by Bernard Michel and in that paper there was a new concept put out, concerning the "aspect ratio", the ratio of the width of the structure to the ice thickness. When we look at its effect in a number of papers in the literature, Michel says perhaps this is nothing more than another way of looking at the strain-rate: a very interesting idea.

Where are we to go in this area? One of the unknowns of course is when we get to very large structures; when the ice pushes against the structure, I am sure we are not going to see failure simultaneously along the entire structure, whether it is a vertical structure or a horizontal structure, and there is a whole unknown area in here that could be discussed if you so wish.

In the field of bearing capacity, we had a paper by M. D. Coon who emphasized the importance of natural forces in the ice sheet such as wind forces, thermal stresses, etc.; he also mentioned such things as trying to get more information about the stress in the ice sheetwhat effect a biaxial stress state or perhaps creep processes would have. We had an excellent paper on the moving-load problem with important new data in an area in which there are very few data available in the literature.

MELlor: I would like to seize on one remark you made in passing. You mentioned failure in biaxial stress fields. I myself have been struck by the absence of discussion of failure criteria in multiaxial stress states.

P. TRYDE: I agree with you. I feel, as you do, that one thing has been left entirely out, that is the rupture mechanics-how the stresses interact; it is not a simple tensile or compression or shear because it is a combination of these, and we lack any new developments comparable to what was done by Coulomb many years ago; I think we should be able to do something more on these lines, and I hope somebody will work on that. We are trying in a theoretical way to apply some of the developments that have been used in soil mechanics. Soil mechanics is a very good example of a science which has developed within the last 25 years.

Mellor: I would just mention that there is a group at the South-West Research Institute in San Antonio, Texas, an unlikely place for ice research, who are trying to get something going on a study of the fracture criterion for ice. It is a complicated problem, because I think we can tell right at the outset that it is going to be qualitatively a different sort of failure criterion in the ductile mode (creep rupture) than in high-rate brittle fracture, where bulk stress is clearly going to have an effect on strength and yielding. Bulk stress does not appear to have much of an effect when you get down to the creep range. 
D. V. REDDY: There is a considerable need for adequate dynamic measurements of ice forces and structural responses as the present records are too meagre. The oil companies and research institutes and universities should collaborate in field measurements on test structures or existing structures.

[Written addition:] The importance of frequency-dependence on ice-force specification should be studied more intensively (both analytically and experimentally). Stochastic studies are particularly important. Ice-structure interaction is a cause-effect study and is no less important than studies on the material properties of ice. The two areas should be considered as complementary.

MeLlor: I would agree that this is important. I have not worked in this field but I have wondered to what extent we should be worrying about compliance of measuring devices in getting these records. As we know, in any kind of compression or indentation test, the compliance of the device that is sensing the measurement, or the compliance of the device that is applying load, is very important to the kind of record we get out; especially if it is anything that has a time-series sort of response, and the frequency is related to the frequency of the measuring or loading device.

L. W. GolD: I also consider that this is a very important question, but it is one of those questions that is easier to state than answer, and when you think of the forces that you are attempting to measure in the field, one realizes that you are talking about quite a large and expensive structure and not every laboratory can afford to construct one, and so in this problem in particular there is a very great need for whoever has that need for information to be prepared to invest in a structure. But there is another aspect of this and that is that there are many structures around and it would be very useful to be able to hang on to the side of them an appropriate instrument for measuring forces, and to have some confidence in the information produced; I think that is an area of instrumentation that could receive some attention. I think there are possibilities of developing something that might be relatively inexpensive that makes use of structures that are already in existence.

WEEKS: I thought that Mr Danys's paper was very interesting in the sense that he presented a large number of curves which you could use only if you knew the correct values of the applicable parameters. This points out the fact that many of the basic properties that we need to know are not well known, and not only that, the particular types of ice that we need to design against are even less well known. By that I mean that if we were to go north of Alaska and walk off the coast and find a nice piece of uniform sea ice, just the sort we invariably select to study, that would not be the piece of ice that the designer is interested in. He is interested in the piece of ice that causes the, say, roo year ice force. He wants to design against a rare event, and the question is what are the appropriate ice thicknesses, ice properties, and ice behaviour that combine to make these rare events.

MelLor: I do agree with you, but of course the engineer is in an unenviable position. He is not like a scientist; he has to come up with an answer even if it is the wrong one. On this business of measuring properties in the field, it is the conservative number that the designer often needs to work with, and that is why it may be a mistake to put enormous efforts into trying to examine a lot of variables and parameters in the field. Maybe it makes more sense to study these things in the testing laboratory and then go out in the field and just get some index number for a carefully specified set of conditions just to see where your material plugs into the scheme of things.

J. Schwarz: Up to a depth of $2 \mathrm{~m} \mathrm{I}$ would say we can predict the forces pretty well on the basis of model tests-small-scale tests verified by full-scale tests-but no data are available for wider structures, and this case cannot be solved by theoretical approaches alone, by 
fracture criteria, because if the structure gets wider other forces such as gravity become important and maybe even become dominant.

Nevel: I want to change the subject to bearing capacity. I see one great need. Presently, as you know, they are drilling from the ice sheet in the Canadian Archipelago and are talking about loads of a few million pounds over a three to four month period-very heavy loads. So We are looking at the creep processes in the ice and I do not care what analysis you do on the creep of ice, all the theories predict that the stresses decrease in time. Yet in fact experiments show that, if you set a load on the ice, after a certain time the ice will start cracking and failing under the load, and yet the stresses are decreasing, so there is a great deal to be done here in terms of finding what controls strength and how creep processes are affecting strength.

MELLOR: I am going to have to cut this off now and ask our ove rworked President, Marcel de Quervain, to apply the perspective of his experience in telling us what we have heard about avalanches.

\section{Avalanches AND Blowing SNOW}

M. R. DE Quervain: I would like to approach the question rather from the side of applied work. We are having a meeting on applied glaciology. We should not forget that we have rejected some papers with excellent theoretical studies on our subjects, and have tried to bring in the ones which deal with the practical problems. Therefore I do not want to review the basically scientific work that has been also presented, but rather to start out from the practical point of view. Avalanches-what should we know in a form th at can be applied? We have to understand the mechanism of fracture, just to be ready to p redict avalanches and to prevent them. We have to know about the frequency of avalanches in the frame of our zoning. We have to forecast avalanches to calculate run-out distances and impact pressures, and then, on the side of fighting avalanches, apply avalanche release, avalanche fencing, and all these things. In all these fields, certainly, very good progress has been made.

In the field of mechanism of fracture, I think the picture of the depth-hoar avalanche or the old-snow fracture has been in the forefront of presentations, whereas we have to know and remember that about $90 \%$ of the avalanche accidents, are caused by new-snow avalanches, which may have a base at a surface-hoar layer or may not. The frequency of new-snow avalanches is related to the statistics of snowfall on the one hand and to the mechanics of new snow on the other, and what we need is some sort of combined statistics on the occurrence of fracture, so this might be a theme that is still open. I think with respect to depth hoar and surface hoar as elements of fracture formation we have now had a new and very good approach and have heard some new ideas and also, importantly, have confirmed some rather old ones.

About frequency of avalanches-this is a subject which has to be investigated. Avalanche forecasts - I think there have been two interesting pieces of news that we have heard: one is the acoustic warning given by the avalanches themselves-I think that might be a very good tool in future. On the other hand much progress is being made on the statistical treatment of avalanche forecasts and we have learned that they go in parallel in different areas compared with the conventional method, I would say they are still behind for practical application. It may take some more time to obtain a quantitative basis for statistical forecasts, and I think one has to aim at including the old-snow conditions, which are as yet not involved in numerical forecasting.

About run-out distances, we have learnt that the turbulent friction of avalanches is very variable. In the formulae widely applied, however, this turbulent friction is just a figure. The kinetics and dynamics of the powder avalanche have been well demonstrated by models, but the question is: have we bridged from the model to the result we need-the run-out distances of the powder avalanche? Somehow we have to know the density distribution in our model avalanche as well as in natural avalanches. 
Impact pressures - extremely high impact pressures have been reported some time ago from Japan, and we certainly have to check a little more concerning the reason. They may be rather difficult to understand even in the context of energy loss. I think a kind of explosion or something like that is necessary to produce impact pressures over 200 tonnes $\mathrm{m}^{-2}$ or $2 \times 10^{6} \mathrm{~Pa}$.

In avalanche release we have heard about very interesting and striking new developments, on the one hand concerning the real effects of explosions on snow and on the other hand of new methods of shaking or pushing the snow, which should be followed-up closely. What is missing, as I said in the discussion, are tests which will tell us whether a slope which has been shaken without releasing an avalanche is now stable or not.

Snow pressure forces on structures are an old problem, but hopeful new solutions have been presented: the three-dimensional solution for pressure on a wall, based on the finite element method. This is progress we have badly needed for a long time, but we still need to transform it into simple general formulae for the engineer.

For ice avalanches, the possible forewarning from hyperbolic velocity curves is also very hopeful. We should in future be confident, if we are aware of such an acceleration, that we can pick the right moment to issue warnings and maybe to evacuate the place.

Mellor: Does anyone have any thoughts about the avalanche dynamics question and avalanche impact? This seems such a terribly difficult problem that one almost despairs of treating the detailed mechanics and wonders whether we should not fall back onto simple energetics or power considerations without worrying too much about the intimate details of what is going on.

S. F. Ackley: One thing that struck me in Hopfinger's film was that the turbulent structure that appears on the top of powder-snow avalanches seems quite similar to some other instabilities such as gravity waves in the atmosphere in the formation of these eddies. I do not know whether it has been or should be studied, but maybe some of the same instability criteria that apply to some of these other problems might also apply to avalanches.

MELLOR: Maybe that is more on the theoretical side unless it has an influence on the speed of fall.

ACKLEY: I think it would, because there seemed to be a reversal in the way that this front moves down. These structures that I think look like Kelvin-Helmholtz instabilities, are indicative of a very large shear; they give a very good mechanism for transferring momentum down and would cause this eddying which would be a tremendous way of picking up more material into the front and transferring it down-slope.

J. W. Glen: I agree that it is a very interesting suggestion and I agree that those pictures were most suggestive in this direction, but I cannot help but be worried about the modelling problems involved in trying to model something as complex as a powder-snow avalanche, because even if you get your density of your liquids right in a liquid model such as that of Hopfinger and Tochon-Danguy, then that presumably is right for one condition-but how on earth are you going to cope with the situation when you are picking up material, throwing it about, and changing the density in a way which I would have thought must depend on the material properties of the snow? It is most unlikely that the model will work with purely liquid material. So for giving us ideas to think about, yes, but for trying to solve the avalanche problem I would have thought it was very dangerous.

MELlor: These are some of the things that have worried people about modelling blowing snow in wind tunnels and water flumes. There is not the slightest chance of conforming to all the various similitude requirements, but maybe there are some overriding ones that do make for some similarity between flow in a water flume and avalanches. 
Now we should move to the last section of our discussion which Dr Glen will lead off for us and will deal with the papers we have heard which touch on friction and adhesion of ice and snow.

\section{FRICTION AND ADHESION}

GLEN: It seems to me that I have been given a rather different task from the others because they all had great areas of this symposium with well-identifiable sets of papers in quite considerable number to try to extract the problem from. Friction, as far as I can see, occurs in the titles of only three pretty diverse papers. Professor Kuroiwa reviewed friction on snow and ice and the work done in Japan, and it would clearly be silly for me to try to produce a mini-review on the same subject. He did talk about friction on both snow and ice with the analogies, but almost certainly the differences, related to the much greater possibility of structural change in the snow case. We had Dr Tusima talking about his friction experiments on single ice crystals, and here it is worth reminding you that he did find that the lowest coefficients of friction occurred near, but not at, the melting point-friction started going up again before the temperature reached melting point. The other paper with friction in its title was that of Danys and others, and there the accent was quite different. It was one that has been touched on in many other papers-how does friction play a role in these snow and ice engineering problems? I think we have got to sound notes of caution all over the place. For one example, the friction of sea ice on a structure will surely be affected by the existence of brine channels as ready sources of liquid in a way which may not affect cold friction of other forms of ice. I know nothing about this subject: are the forces exerted by lake ice on structures inserted in it in fact bigger than those exerted by comparable sea ice? Also there is the question that has hardly been touched on here of what the ice is having its friction against and the role played by adhesion in this. The place where it was touched on, where it has a big commercial interest, was the bottom side of ski, where we did have the question of ski-waxes discussed but then rather discreetly removed from our view again. But ought we to be putting something like ski waxes on our lighthouses or our ships? Do people put polytetrafluorethylene on things to try and make the ice ride up? I do not know, I am just asking questions which seem to come up to me as a physicist.

Mellor: The answer is yes, we do put on something like ski wax to reduce at least the adhesion of ice on materials.

E. R. Pounder : I am not sure that I can answer Glen's question about the difference between salt-water ice and fresh-water ice, but I do know that one of the worst cases of icebreaking possible is when you are breaking ice cover with fresh snow on it. As soon as the ice gets tilted down and rubs the wet snow against the side of the ship, you get the worst possible friction on an icebreaker that I have encountered.

K. R. Croasdale: I suppose in general that is a good reason for not having downward breaking structures. Most of the structures we have looked at to date have been ones where we forced the ice to break upwards, so we should not have that problem. There is a point here that was raised by Dr Glen - this business about whether you have to deal with saline ice or fresh ice and whether the friction is different between the two is certainly an important one. Referencing back to some of the problems we are facing in the Beaufort Sea, we usually come back to the conclusion that you really only have to worry about fresh ice because the ice type that is likely to put the largest forces on the structure will probably be fresh since it is a multiyear ridge. Whether the fact that it is floating in sea-water would locally affect that interface and its friction we do not know. There are some very elaborate designs in existence for dealing with friction and adhesion on sloping structures, some of which use internal heating close to 
the skin of the structure so that any adhesion which might occur during the period when the ice is stationary can be eliminated. Obviously it would be somewhat catastrophic if a structure was designed for fairly low ice forces based on ice failing in bending and the ice decides to freeze to the structure.

Mellor: Your mention of heating reminds me of the valid comment made in one of the presentations that the specific energy required for melting in de-icing is very much higher than the specific energy for breaking ice. However, what we have to remember with these high specific-energy processes, like heating or hyper-velocity water-jet cutting, is that they can sometimes be used in places where they have to attack only a very small volume, and so they are not necessarily ruled out. In fact, electrical heating is being put into locks on the St Lawrence Seaway at high pool elevation.

Nevel: One of the big difficulties about putting substances on structures is abrasion. Many materials which you put on, are gone in a day or so and the ice goes through. Particularly in the problem of icebreaking recently Wärtsilä in Finland have used a solid-free epoxy to coat the hull of their ship along the ice interface and this I guess has stuck on the ship fairly well and has reduced the friction.

Mellor: Yes that is an important practical point. I guess that is why we put polyethylene on the base of skis and not PTFE (Teflon).

TRYDE: Air bubbles have been used to reduce friction on ships.

WEEKS: I know there has been considerable discussion of whether or not this effect was real. I do not know if this question has ever been resolved.

O. Orheim: I think in the Wärtsilä wharf if I remember right, they use the air bubbles not so much to reduce friction as to lift up the ice. The latest icebreaker that they have been building in the last couple of years they put on a great deal of air with the idea of lifting up the ice and getting it away.

J. V. Danys: Our paper was the result of a broader study in which we realized that friction had a significant influence on the sloped surfaces and we analyzed that by numerical and analytical methods and obtained the number of curves and tables needed for design. Then we needed to have, as the next step, some design values of friction, and had a problem here because there are no reliable data available for friction of ice against materials of structures. We need more testing here, especially under field conditions, i.e. of large and thick ice-floes against structures. At present, correlation between small-scale tests in the laboratory and actual field conditions is impossible. In Canadian experience, almost all small light-piers in the lakes and rivers have steel-plate protection which reduces the friction.

Schwarz: One important problem in this respect is how we measure the friction coefficient? Some very wrong methods have been used such as pulling or turning a rough material over the ice surface. After a short distance the cavities of the rough material will be filled with ice crystals and you measure the friction between ice and ice. 